\title{
In vivo evaluation of Monascus-fermented durian seed for antidiabetic and antihypercholesterol agent
}

\author{
${ }^{1 *}$ Nugerahani, I., ${ }^{1}$ Sutedja, A.M., ${ }^{1}$ Srianta, I., ${ }^{2}$ Widharna, R.M. and ${ }^{1,3}$ Marsono, Y. \\ ${ }^{1}$ Department of Food Technology, Faculty of Agricultural Technology, Widya Mandala Catholic \\ University Surabaya, Jalan Dinoyo 42-44 Surabaya, East Java, Indonesia \\ ${ }^{2}$ Faculty of Pharmacy, Jalan Dinoyo 42-44 Surabaya, East Java, Widya Mandala Catholic \\ University Surabaya, Indonesia \\ ${ }^{3}$ Department of Food and Agricultural Product Technology, Faculty of Agricultural Technology, \\ Gadjah Mada University, Jalan Flora 1, Bulaksumur, Yogyakarta Indonesia
}

\section{Article history: \\ Received : 19 April 2017 \\ Received in revised form : \\ 22 May 2017 \\ Accepted : 23 May 2017 \\ Available Online : \\ 30 May 2017 \\ Keywords: \\ Monascus \\ Durian seed \\ Blood glucose \\ Diabetes \\ Hypercholesterol}

\section{DOI:}

http://doi.org/10.26656/

fr.2017.3.023

\begin{abstract}
Monascus-fermented durian seed (MFDS) had been developed previously. This research was aimed to evaluate the MFDS for antidiabetic and antihypercholesterol agent with in vivo method using Wistar rat. The MFDS was produced by inoculating the spore suspension of Monascus sp. KJR2 into durian seed cuts and then incubated at room temperature $\left(30^{\circ} \mathrm{C}\right)$ for 14 days. The product was dried and ground to produce MFDS powder. The MFDS suspension was evaluated its lowering blood glucose and cholesterol concentration in vivo using male Wistar rats. Administration of $2 \mathrm{~mL}$ of product suspensions at the level of $0.05 ; 0.10$; and $0.15 \mathrm{~g} / 2 \mathrm{~mL}$ for 28 days decreased $12.89 \%$ of blood glucose and $49.3 \%$ serum cholesterol concentration in the rats. Higher level of MFDS suspension resulting higher effectiveness of the lowering blood glucose and total cholesterol. MFDS also improved lipid profile including HDL-cholesterol, LDL-cholesterol and Triglyceride levels.
\end{abstract}

1. Introduction

Monascus-fermented product, especially Monascus-fermented rice has been used by Asian people for centuries as natural food colorant, food supplement and traditional medicine. During solid state fermentation, Monascus produces various secondary metabolites primarily pigments and monacolines with various bioactivities, and the fermented products showed possitive health effects (Chang et al., 2006; Chen et al., 2006; Lin et al., 2008; Shi et al., 2010; Shi et al., 2012).

Monascus-fermented durian seed is a fermentation product of Monascus on durian seed as the substrate. Our previous finding showed that the Monascus-Fermented Durian Seeds (MFDS) contain pigments (yellow, orange and red pigments), monacolin $\mathrm{K}$ and phenolic (Srianta, Novita and Kusumawati, 2012; Srianta et al., 2012). Some researchers also reported that Monascus-fermented products contain monacolin $\mathrm{K}$ (Chairote et al., 2008). In vitro antidiabetic assay i.e. $\alpha$-glucosidase inhibition activity of MFDS extract showed that the MFDS potent to be developed as antidiabetic product (Srianta et al., 2013). Monacolin K posses lowering blood cholesterol effect through inhibition of

HMGCoA reductase activity, enzyme in cholesterol biosynthesis pathway (Endo, 1980; Endo, 1988). Li et al. (1998) reported the antihypercholesterol activity of Monascus-fermented rice. However, evaluation of antidiabetic and antihypercholesterol of MFDS have not been studied yet. Objective of this research was to evaluate in vivo antidiabetic and antihypercholesterol activities of MFDS.

\section{Materials and methods}

\subsection{MFDS production}

Durian seeds were boiled in a $\mathrm{CaCO}_{3}$ solution of $5 \% \mathrm{w} / \mathrm{v}$ for $10 \mathrm{~min}$ to remove the mucus. After the seed coat were peeled off, the seeds were cut into small size. A $50 \mathrm{~g}$ of small cut durian seed was transferred into $300 \mathrm{~mL}$ flask, mixed thoroughly, autoclaved at $121^{\circ} \mathrm{C}$ for $15 \mathrm{~min}$, then left to cool at room temperature, inoculated with the spore suspension of Monascus sp. KJR2 and incubated at room temperature $\left(30^{\circ} \mathrm{C}\right)$ for 14 days in static conditions (with manual shaking daily). Monascusfermented durian seed were dried in an oven at $45^{\circ} \mathrm{C}$ for 24 hours and ground. 


\subsection{In vivo evaluation of MFDS antidiabetic and antihypercholesterol activities}

The committee of ethical clearance of the Integrated Research and Testing Laboratory Gadjah Mada University approved this in vivo experiment with ethical clearance number of 142/KEC-LPPT/ IV/2014. Animals were treated in accordance for the proper care and use of laboratory animals.

Twenty four (24) male Wistar rats about 2 months old (weight range of 250-300 g) were adapted for a week with feeding of standard feed (AIN-93M) (Table 1). At the end of the adaptation, blood glucose level and lipid profile (total cholesterol, HDLcholesterol, LDL-cholesterol, dan Triglyceride) of blood serum were analyzed. After that, the rats were fed with high cholesterol feed for a week to make hypercholesterol rats, with total cholesterol of $>130$ $\mathrm{mg} / \mathrm{dL}$. The high cholesterol feed was formulated as standard feed with an addition of $1 \%$ of cholesterol (Matos et al., 2005). Then, the rats were induced to diabetic by injecting of streptozotocin (STZ) $65 \mathrm{mg}$ / $\mathrm{kg}$ and Nicotineamide (NA) $230 \mathrm{mg} / \mathrm{kg}$ body weight (Szkudelski, 2012). The rats were fed with standard feed for 5 days until the rats got diabetic (Marsono et al., 2003). During the diabetic induction, to prevent the rats of having hypoglycemic condition they were given dextrose solution by forced feeding.

Table 1. Composition of the diets ( $\mathrm{g} / 1000 \mathrm{~g}$ of diet)

\begin{tabular}{lcc}
\hline \multicolumn{1}{c}{ Component } & $\begin{array}{c}\text { Standard *, } \\
(\mathrm{g})\end{array}$ & $\begin{array}{c}\text { High } \\
\text { Cholesterol**, } \\
(\mathrm{g})\end{array}$ \\
\hline Corn starch & 620.692 & 610.692 \\
Casein & 140 & 140 \\
Sucrose & 100 & 100 \\
Soybean oil & 40 & 40 \\
Cellulosa & 50 & 50 \\
Cholesterol & - & 10 \\
Mineral mix & 35 & 35 \\
Vitamin mix & 10 & 10 \\
L-cystine & 1.8 & 1.8 \\
Cholin bitartrate & 2.5 & 2.5 \\
tert-butyl hydroquinone & 0.008 & 0.008 \\
(TBHQ) & 1000 \\
\hline Total & \\
\hline Source: *) Reeves et al. (1993) & \\
$\quad * *)$ Hypercholesterolemic diets were suplemented \\
$\quad$ with 10 g of cholesterol per kg of diet, at the \\
$\quad$ expense of starch.
\end{tabular}

The rats were divided randomly into 4 groups of 6 rats i.e.: Control group fed with standard feed, and the other groups were fed with standard fed and given $2 \mathrm{~mL}$ of $0.05 \mathrm{~g}$ MFDS suspension (MF0.05), 0.10g MFDS suspension (MF0.10) and 0.15g MFDS suspension (MF0.15), respectively.

The feed and water were given ad libitum and MFDS suspension was administered by forced feeding daily for 28 days. The rats were weighed at the early of the experiment and every week during the experiment. Analysis of blood glucose and lipid profile were carried out every week, after 12 hours fasting.

\subsection{Data analysis}

The obtained data were calculated for the average. The data obtained after 28 days treatment period were analyzed statistically using Analysis of varians with $\alpha=5 \%$ and Least Significant Difference with $\alpha=5 \%$.

\section{Results and discussion}

Ahigh cholesterol diet and streptozotocin injection resulted in hypercholesterol (total cholesterol of blood serum were 211 and $225 \mathrm{mg} / \mathrm{dL}$ ) and diabetic (glucose levels of blood serum were in a range of 216 and $220 \mathrm{mg} / \mathrm{dL}$ ) rats. Figure 1(a) showed that the body weight of all the rats with MFDS treatments increase, while the control tend to decrease during the experiment. Figure 1(b) showed that the control feeding intake higher than those of the treatments. This rats weight decreasing during experiment seem was due to the effect of diabetes on rats. Diabetic rats tend to polyuria, polydipsia, polyfagia, and loose body weight. In a research by Akbarzadeh et al. (2007), it was shown that consumed food in normal rats was 10 \pm 2 grams, while in streptozotocin induced diabetic rats was $45 \pm 5$ grams, the water consumed by normal rats was around $35 \mathrm{ml}$, while in streptozotcin induced diabetic rats was $150 \mathrm{ml}$, and the volume of urine in normal rats was $10 \pm 1 \mathrm{ml}$ and in the streptozotocin induced diabetic rats was $130 \pm 5 \mathrm{ml}$.

Figure 2 is blood glucose levels during the experiment. Streptozotocin destroyed the B cells of the pancreas by DNA alkylation, which led to B cell necrosis (Szkudelski, 2001). From the figure, it was concluded that the glucose level for all groups were normal, and then the treatment using streptozotocin was successful to increasing the glucose level up to a constant level at the end of the period of induction. Administration of MFDS suspension at the level of $0.05 ; 0.10$; and $0.15 \mathrm{~g} / 2 \mathrm{~mL}$ for 28 days showed lowering blood glucose level effect in the rats. Higher level of MFDS suspension, higher effectiveness in lowering blood glucose of the rats. Chang et al. (2006) found similar result that oral administration of 


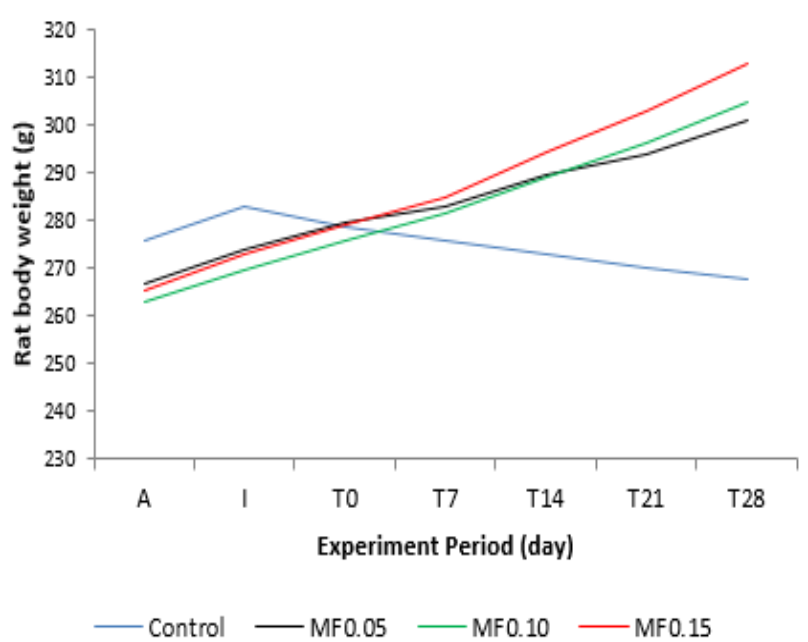

(a)

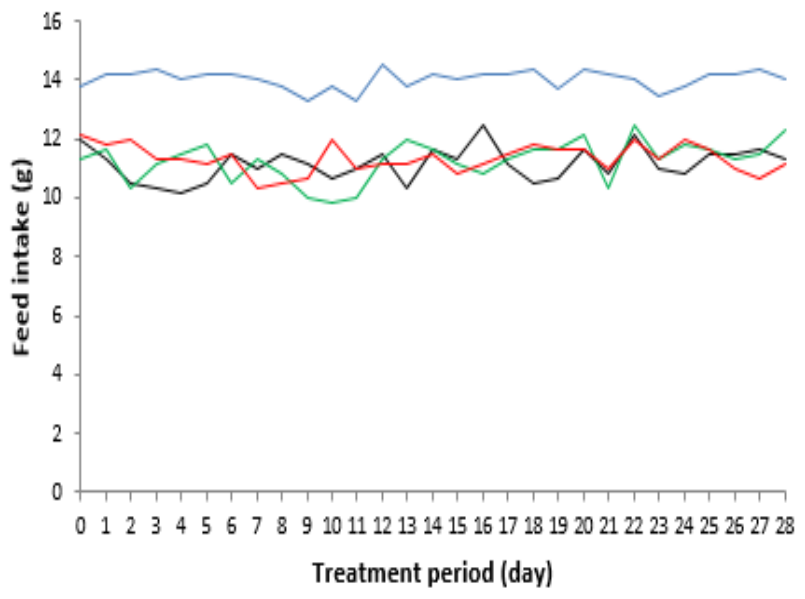

(b)

Figure 1. Rats body weight (a) and feed intake (b) during experiment. A (adaptation); I (induction); T0 (day 0 of treatment); T7 (7 days of treatment); T14 (14 days of treatment); T21 (21 days of treatment); T28 (28 days of treatment).

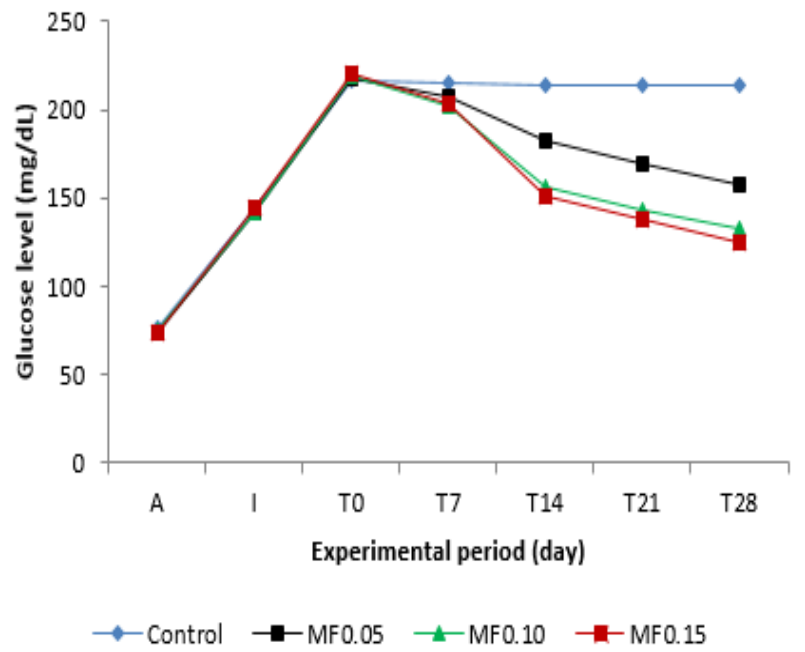

Figure 2. Blood glucose levels (mg/dL) during experiment. A (adaptation); I (induction); T0 (day 0 of treatment); T7 (7 days of treatment); T14 (14 days of treatment); T21 (21 days of treatment); T28 (28 days of treatment).
Monascus-fermented rice at $50-350 \mathrm{mg} / \mathrm{kg}$ reduced plasma glucose of streptozotocin-diabetic rats. The decreasing plasma glucose was in a dose depedent manner. Shi and Pan (2010) also reported that feeding of different type of Monascus-fermented products i.e. Monascus-fermented rice, Monascus-fermented dioscorea and Monascus-fermented adlay reduced blood glucose levels of diabetic rats after after 8 weeks of feeding.

Those effects might be due to MFDS posses $\alpha$-glucosidase inhibition activity, which related to the phenolic content of the product (Srianta et al., 2013). Moreover, during fermentation on durian seed substrate, the Monascus purpureus produce yellow, orange and red pigments (Srianta et al., 2012). The pigments might be contribute to the antidiabetic activity. Lee et al. (2011) reported that yellow pigment, Monascin, was able to improve insulin sensitivity through serine/threonine protein kinases pathway by stabilizing PPAR- $\gamma$ structure, preventing its phosphorylation, and inhibiting c-Jun N-terminal kinase activation. Shi et al. (2012) suggest that the Monascin has a therapeutic potential on diabetes and diabetes-associated oxidative stress complications. Higher level of MFDS suspension has higher contents of phenolic and pigments which might be resulted higher effectiveness in lowering blood glucose. In this experiment, blood glucose level of the MF0.1 and MF0.15 group decreased by $5.76 \%$, and $12.89 \%$ respectively when compared to those glucose levels after induction. The greatest effec of decrease in blood glucose level was achieved in 2 weeks after the treatment, followed by constant decrease until the end of experiment ( 1 month MFDS treatment).

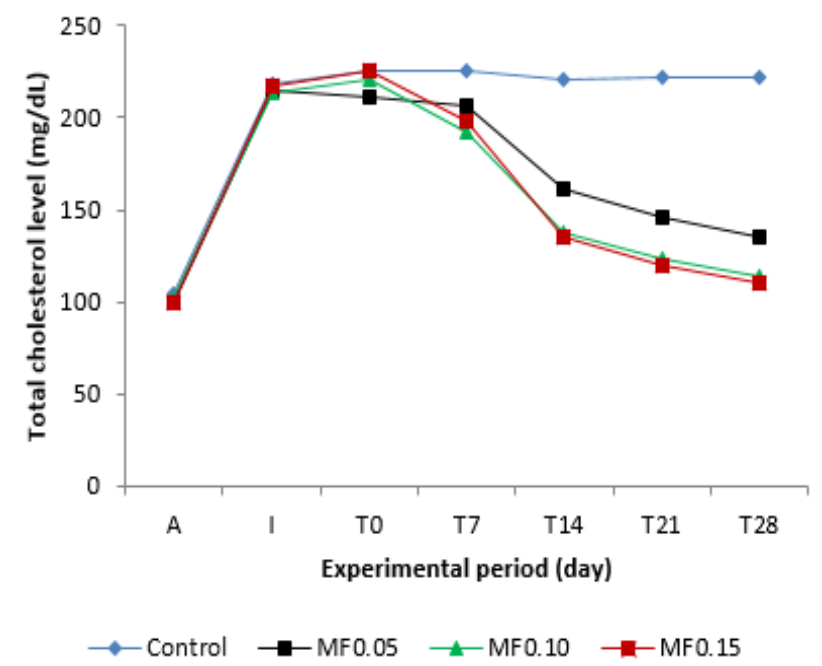

Figure 3. Blood cholesterol levels (mg/dL) during 28 days experiment. A (adaptation); I (induction); T0 (day 0 of treatment); T7 (7 days of treatment); T14 (14 days of treatment); T21 (21 days of treatment); T28 (28 days of treatment). 
Total cholesterol levels during experiment is shown in Figure 3. High cholesterol feeding resulted high blood total cholesterol level in all groups of rats. All treatment was succesful to lowering the blood cholesterol levels during 28 days experiments. Higher level MFDS resulted lower total cholesterol level. Total cholesterol level of the MF0.15 group decreased 49.3\%. Yeap et al. (2014) found similar results that administration of Monascus-fermented rice water extracts (MARDI Monascus-fermented rice and Commercial Monascus-fermented rice) at 60 $\mathrm{mg} / \mathrm{kg}$ reduced blood cholesterol levels signicantly.

Table 2. Blood LDL-c, HDL-c and triglyceride levels (mg/dl) during 28 days experiment

\begin{tabular}{lccccc}
\hline \multirow{5}{*}{ Group } & \multicolumn{5}{c}{ Period (week) } \\
\cline { 2 - 6 } & 0 & \multicolumn{5}{c}{2} & 4 \\
\hline Control & 100.3 & 102.86 & 103.35 & 102.42 & $103.2^{\mathrm{d}}$ \\
MF0.05 & 96.15 & 99.69 & 93.70 & 70.00 & $63.26^{\mathrm{c}}$ \\
MF0.10 & 95.24 & 99.29 & 98.48 & 57.58 & $51.15^{\mathrm{b}}$ \\
MF0.15 & 99.7 & 104.19 & 103.15 & 57.98 & $48.05^{\mathrm{a}}$ \\
\hline \multicolumn{5}{c}{ HDL-c level (mg/dL) } \\
\hline Control & 23.29 & 22.47 & 21.40 & 23.42 & $22.22^{\mathrm{a}}$ \\
MF0.05 & 28.38 & 27.31 & 29.55 & 39.94 & $47.48^{\mathrm{b}}$ \\
MF0.10 & 28.68 & 27.46 & 34.79 & 53.45 & $60.90^{\mathrm{c}}$ \\
MF0.15 & 25.91 & 24.82 & 34.50 & 61.93 & $70.56^{\mathrm{d}}$ \\
\hline \multicolumn{5}{c}{ Triglyceride level (mg/dL) } \\
\hline Control & 141.33 & 146.94 & 147.79 & 145.40 & $148.28^{\mathrm{c}}$ \\
MF0.05 & 135.90 & 142.05 & 131.20 & 100.30 & $93.12^{\mathrm{b}}$ \\
MF0.10 & 133.64 & 140.06 & 120.85 & 84.01 & $79.37^{\mathrm{a}}$ \\
MF0.15 & 139.22 & 145.57 & 127.70 & 80.09 & $74.44^{\mathrm{a}}$ \\
\hline Note: & different & character in & the same & column & indicated a \\
& significantly different at $\alpha=5 \%$ & & \\
\hline \multicolumn{5}{c}{ a }
\end{tabular}

Table 2 is blood LDL-c, HDL-c and triglyceride levels data during the experiment. HDL-c ("good cholesterol") and LDL-c ("bad cholesterol") are the forms of cholesterol circulated in the blood. HDL is called good cholesterol as it has little cholesterol and high in protein content, while LDL is the opposite way. LDL is the source of artery clogging plaque, while HDL actually works to clear cholesterol from the blood (Ma, 2006).

As seen in Table 2, HDL in the MF0.15 group was highest, while the LDL level was the lowest. Triglycerides are another form of fat in the bloodstream. High level of triglycerides indicated high risk of cardiac disease. A high triglycerides level with high LDL level or lower HDL level increases the speed of atheroschlerosis, which increases the risk of heart attack and stroke (Ma, 2006). In this experiment, triglycerides of the MF.015 group decreased by $54.88 \%$ from the hypercholesterol level, the highest decrement compared to the other treatment level, while the control group triglycerides level increased by $5.46 \%$.

It is concluded that MFDS improved lipid profile including lowering total cholesterol, LDLcholesterol, triglyceride and increasing HDLcholesterol. Yeap et al. (2014) found similar results that administration of Monascus-fermented rice water extracts (MARDI Monascus-fermented rice and Commercial Monascus-fermented rice) at $60 \mathrm{mg} /$ $\mathrm{kg}$ decreased blood cholesterol, triglyceride, LDLcholesterol levels and increase HDL-cholesterol significantly.

The mechanism was might be due to combination effect of bioactive compounds in the MFDS. The MFDS contain monacolin $\mathrm{K}$ and pigments (Srianta et al., 2012). Monacolin $\mathrm{K}$ is well known cholesterol lowering agent and it has been used for hypercholesterol drug widely. Its action is to inhibit HMG-CoA reductase, the first enzyme in cholesterol biosynthesis pathway, activity. Jou et al. (2010) reported that monascus yellow pigments, Monascin and Ankaflavin, might reduce triglyceride accumulation and suppress expression of adipocytespecific transcription factors to decrease proliferation and differentiation of preadipocyte. Both of them might also promote mature adipocyte delipidation by releasing glycerol and downregulating the HR-LPL activities. According to Li et al. (1998), Monascusfermented product contain not only inhibitors of HMG-CoA reductase, but also monosaturated fatty acids, sterols, proteins, saccharide, isoflavone and its glycoside, saponin and sapogenin, and trace elements such as selenium and zinc. They suggest that combination of its total constituents might effect on the improving cholesterol status. However, the precise contribution need further study.

Drugs lowering cholesterol are clofibrate, gemfibrozil, nicotinic acid (niacin), resin, statin, bile acid sequestrants and fibrates. MFDS was similar to statin as it lowers the LDL and triglyceride and has mild effect in increasing HDL (Yee et al., 2004; Zhang et al., 2008). Statins blocks the production of cholesterol in the liver itself (Ma, 2006). However, there are side effects of these drugs, such as muscle aches, abnormal liver function, allergic reaction (skin rashes), heartburn, dizziness, abdominal pain, constipation and decreased sexual desire) (Ma, 2006). In this experiment, side effects of MFDS both in physical form and in molecular form in short and long term was not observed yet. 


\section{Conclusion}

Administration of MFDS suspension at the level of $0.05 ; 0.10$; and $0.15 \mathrm{~g} / 2 \mathrm{~mL}$ for 28 days showed lowering blood glucose and cholesterol effect. Higher level of MFDS suspension, higher effectiveness in lowering blood glucose and cholesterol levels of the rats. Moreover the treatments also improved blood lipid profile including HDL cholesterol, LDL cholesterol and triglyceride levels. Further study on side effects of MFDS need to be carried out.

\section{Acknowledgment}

Thanks to Directorate General of Higher Education, Ministry of National Education, Republic of Indonesia for the financial support through competitive research Penelitian Hibah Bersaing with contract number of $005 / \mathrm{SP} 2 \mathrm{H} / \mathrm{PDSTRL} / \mathrm{K} 7 / \mathrm{KL} /$ II/2013.

\section{References}

Akbarzadeh, A., Jamshidi, S., Norouzian, D. and Allahverdi, A. (2007). Indian Journal of Clinical Biochemistry. Induction of diabetes by Streptozotocin in rats. Indian Journal of Clinical Biochemistry, 22 (2), 60-64.

Chairote, E., Chairote, G., Niamsup, H. and Lumyong, S. (2008). The presence and the content of monacolins in red yeast rice prepared Thai glutinous rice. World Journal of Microbiology and Biotechnology, 24, 3039-3047.

Chang, J.C., Wu, M.C. Liu, I.M. and Cheng, J.T. (2006). Plasma glucose-lowering action of Hon-Chi in streptozotocin-induced diabetic rats. Hormone Metabolism Research, 38, 76-81.

Chen, C.C. and Liu, I.M. (2006). Release of acetylcholine by Hon-Chi to raise insulin secretion in Wistar rats. Neuroscience Letter, 404, 117-121.

Endo, A. (1980). Monacolin K, a new hypocholesterolemic agent that specifically inhibits 3-hydroxy-3methylglutaryl coenzyme A reductase. Journal of Antibiotics (Tokyo), 33, 334-336.

Endo, A. (1988). Chemistry, biochemistry and pharmacology of HMG-CoA reductase inhibitors. Klin Wochenschr, 66, 421- 427.

Jou, P.C., Ho, B.Y., Hsu, Y.W. and Pan, T.M. (2010). The effect of Monascus secondary polyketide metabolites, monascin and ankaflavin, on adipogenesis and lipolysis activity in 3 T3-L1. Journal of Agricultural and Food Chemistry, 58, 12703-12709.

Lee, B.H., Hsu, W.H., Liao, T.H. and Pan, T.M. (2011). The Monascus metabolite monascin against TNF- $\alpha-$ induced insulin resistance via suppressing PPAR- $\gamma$ phosphorylation in $\mathrm{C} 2 \mathrm{C} 12$ myotubes. Food and Chemical Toxicology, 49, 2609-2617.
Li, C., Zhu, Y., Wang, Y., Zhu, J.S., Chang, J. and Kritchevsky, D. (1998). Monascus Purpureusfermented rice (red yeast rice): a natural food product that lowers blood cholesterol in animal models of hypercholesterolemia. Nutrition Research, 18(1), 7181.

Lin, Y.L., Wang, T.H., Lee, M.H. and Su, N.W. (2008). Biologically active components and nutraceuticals in the Monascus-fermented rice: a review. Applied Microbiology and Biotechnology, 77, 965-973.

Ma, H. (2006). Cholesterol and human health. The Journal of American Science, 2(1), 46-51.

Marsono,Y., Noor, Z. and Rahmawati R. (2003). Pengaruh diet kacang merah terhadap Kadar gula darah tikus diabetik induksi alloxan. Jurnal Teknologi dan Industri Pangan, 14(1), 1-6.

Matos, S.L., Paula, H., Pedrosa, M.L., Santos, R.C., Oliveira, E.L., Junior, D.A.C. and Silva, M.E. (2005). Dietary models for inducing hypercholesterolemia in rats. Brazilian Archives of Biology and Technology, 48, 203-209.

Reeves, P.G., Nielsen, F.H. and Fahey, G.C. Jr. (1993). AIN-93 purified diets for laboratory rodents: Final report of the American Institute of Nutrition and ad hoc writing committee on the reformulation of the AIN-76A diet. Journal of Nutrition, 123, 1939-1951.

Shi, Y.C. and Pan, T.M. (2010). Anti-diabetic effects of Monascus purpureus NTU 568 fermented products on streptozotocin-induced diabetic rats. Journal of Agricultural and Food Chemistry, 58(13), 7634-40.

Shi, Y.C. and Pan, T.M. (2012). Red mold, diabetes, and oxidative stress: a review. Applied Microbiology and Biotechnology, 94(1), 47-55.

Srianta, I., Novita, Y. and Kusumawati, N. (2012). Production of monascus pigments on durian seed: effect of supplementation of carbon source. Journal of Pure and Applied Microbiology, 6, 59-63.

Srianta, I., Hendrawan, B., Kusumawati, N. and Blanc, P.J. (2012). Study on durian seed as a new substrate for angkak production. International Food Research Journal, 19(3), 941-945.

Srianta, I., Kusumawati, N., Nugerahani, I., Artanti, N. and $\mathrm{Xu}, \mathrm{G} . \mathrm{R}$. (2013). In vitro $\alpha$-glucosidase inhibitory activity of Monascus-fermented durian seed extracts. International Food Research Journal, 20 (2), 533536.

Szkudelski, T. (2001). The mechanism of Alloxan and Streptozotocin action in B cells of the rat pancreas. Phyisiology Research, 50(6), 537-546.

Szkudelski, T. (2012). Streptozotocin-Nicotineamide induced diabetics in the rat: characteristics of the experimental model. Experimental Biology and Medicine, 237, 481-490.

Yeap, S.K., Beh, B.K., Kong, J., Ho, W.Y., Yusof, H.M., Mohamad, N.E., Hussin, A., Jaganath, I.B., Alitheen, N.B., Jamaluddin, A. and Long, K. (2014). In Vivo Hypocholesterolemic Effect of MARDI Fermented Red Yeast Rice Water Extract in High Cholesterol Diet Fed Mice. Evidence-Based Complementary and Alternative Medicine, DOI: 10.1155/2014/707829 
Yee, A., Majumdar, S.R., Simpson, S.H., McAlister, F.A., Tsuyuki, R.T. and Johnson, J.A. (2004). Statin use in type 2 diabetes mellitus is associated with a delay in starting insulin. Diabetes Medicines, 21, 962-967.

Zhang, S., Yan, X. Zhou, P.C., Huang, C. and Yang, L. (2008). Effects of pravastatin in prevention of diabetes and mechanism thereof: Experiment with non-obese diabetic mice. Zhonghua Yi Xue Za Zhi, 88, 568-572. 